\title{
Ficção científica: utopia ou distopia? Felicidade, angústia e prazer na pós-modernidade
}

Carlos Alberto Machado

Doutor pela Pontifícia Universidade Católica do Rio de Janeiro e docente na Unicentro, departamento de Educação.

E-mail: cipexbr@yahoo.com

Resumo: A proposta do artigo está baseada no interesse em aprofundar estudos de ficção científica, e em procurar fazer um paralelo dos problemas existenciais do mundo contemporâneo, mormente a angústia, citados principalmente pelos autores Richard Sennett, Russsell Jacoby e Zygmunt Bauman, considerados por alguns como pós-modernos. Vários exemplos são citados para corroborar as observações apontadas no texto. Conceitos como felicidade e liberdade são colocados à prova e a ficção científica é usada como exemplo, mostrando o vício tecnológico e a desnaturalização da sociedade. Conclui-se que a imagem da realidade evidenciada em filmes de ficção científica pode auxiliar na reflexão de nossos atos e, dessa forma, tentar contribuir para atitudes futuras.

Palavras-chave: Angústia. Ficção científica. Pós-modernidade. Educomunicação. Sociedade.
Abstract: The aim of this paper is based on the interest in further studies of science fiction, and seek to draw a parallel between the existential problems of the contemporary world, especially the anxiety, mainly cited by Richard Sennett, Russsell Jacoby and Zygmunt Bauman, considered by some as postmodern authors. Several examples are cited to support the comments made in the paper. Concepts such as happiness and freedom are put to the test, while science fiction is used as an example, emphasising the technology addiction and the denaturalization of society. It is ultimately a reflection that the reality seen in science fiction movies may help in the reflection of our actions and thus, trying to contribute to future actions.

Keywords: Anguish; Science Fiction; Postmodernity; Educommunication; Society.

\section{POR QUE ESCOLHEMOS A FICÇÃO CIENTÍFICA (FC)?}

Inicialmente porque na contemporaneidade esse gênero de filme é o mais procurado pela população em geral. Essa busca é consequência, por um lado, da avançada tecnologia que Hollywood vem utilizando cada vez mais em seus produtos cinematográficos e televisivos e, por outro, da forte atração que nar- 
São os filmes de FC que costumam ter mais sucesso na bilheteria ou uma audiência maior, e são também os mais comentados pela mídia, devido, em grande parte, aos efeitos especiais.

A tão almejada felicidade, que é constantemente buscada pelo ser humano contemporâneo, em todas as suas ações, acaba se tornando utópica. A alegria do dia a dia, constantemente confundida com felicidade por alguns, nada mais é do que um pré-requisito desta.

A ideologia cartesiana ou "visão reacionária", que vem carregada nas costas da ciência, demonstra que o homem é recortado ou lido como um livro, algo que se pode perceber em Gattaca ${ }^{1}$, um filme de ficção científica que analisa uma possibilidade assustadora de seletividade: você só será aquilo que seu gene diz que você pode ser. Seus sentimentos não contam em absoluto. Roteiro que lembra muito a ideia original de Huxley, em sua utopia "Admirável Mundo Novo".

1. Gattaca (1997), EUA, de Andrew Niccol.

2. Metrópolis (1927), de Fritz Lang.

3. SENNETT, R. A corrosão do caráter: consequências pessoais do trabalho no novo capitalismo. 9. ed. Rio de Janeiro: Record, 2005, p. 50.

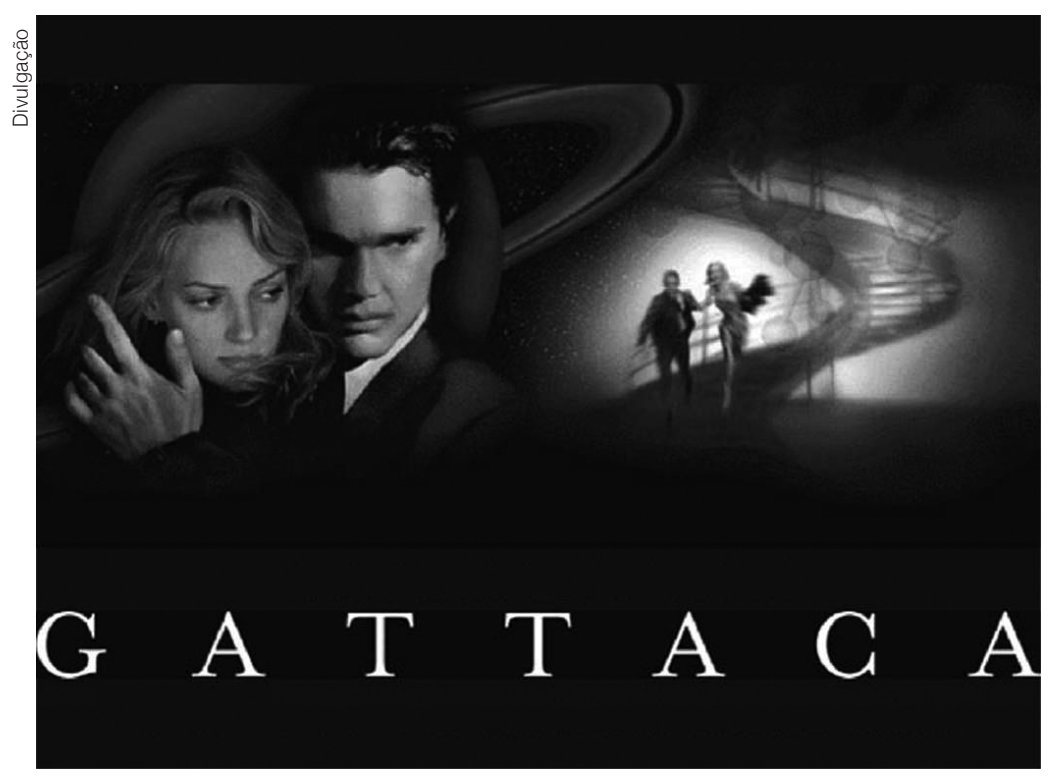

Gattaca, 1997: filme de ficção científica que mostra uma possibilidade assustadora de seletividade.

Com a era da industrialização, em meados do século XIX, tanto Diderot quanto Voltaire acreditavam que a dominação da rotina acalmaria as pessoas. Mas, junto com a rotina, evidenciada em Metrópolis ${ }^{2}$ - e em Tempos Modernos, de Charles Chaplin (Carlitos) -, também veio o tédio com a morte espiritual e a rebelião, tão temida por Platão em sua utópica República. De qualquer forma, mesmo Sennett concorda que um pouco de rotina não faz mal a ninguém, ao contrário: "Imaginar uma vida de impulsos momentâneos, de ação a curto prazo, despida de rotinas sustentáveis, uma vida sem hábitos, é imaginar na verdade uma existência irracional"'.

A era da mundialização evidencia seres humanos "locais" que, ao mesmo tempo que olham com cobiça e desejo os mundos dos outros, procuram aquietar-se em seu próprio meio. Muitos procuram guias para orientá-los, lançando-se numa busca frenética pelos livros de autoajuda, procurando receitas milagrosas. 
Ficção científica: utopia ou distopia? - Carlos Alberto Machado

Entretanto, as receitas não funcionam. Essa busca pode ser identificada em $O$ guia dos mochileiros das galáxias $^{4}$, que fala da necessidade de termos um guia para transitar pelo universo. A ironia está em que, no filme, o guia, na prática, não ajuda em absolutamente nada.

A corrosão de caráter de que fala Sennett começa pela fragilidade das relações entre as pessoas na contemporaneidade. A solidariedade espontânea é abandonada e substituída por uma solidão encontrada na tecnologia eletrônica e no consumismo exacerbado e individual. Troca-se uma forma de submissão de poder por outra, a da carne pela da eletrônica. A legimitividade emocional não é mais encontrada, pois foi substituída pela clara operacionalidade. Apesar disso, o reconhecimento é necessário, como nos recorda Jacoby, a dialogia é uma necessidade humana vital, sem ela não sobrevivemos. Essa necessidade de conexão com o outro é evidenciada por David Cronenberg com o filme eXistenZ (1999), onde jogadores de uma espécie de video game penetram no jogo de forma total, sentimental e corpórea (mente e corpo). O fio de conexão com o jogo é ligado diretamente na medula espinhal, e os estímulos audiovisuais são inseridos diretamente no córtex cerebral.

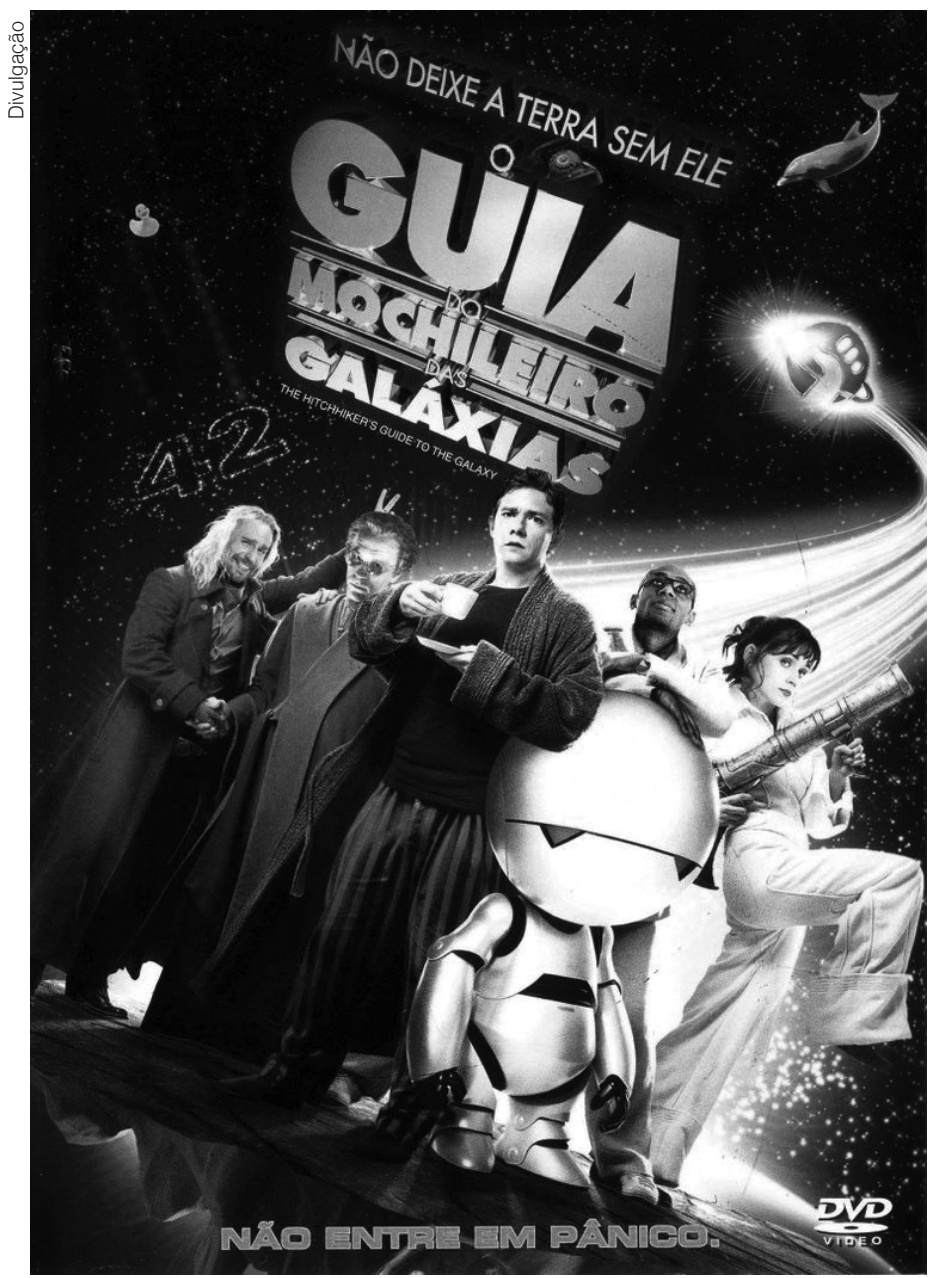

O guia dos mochileiros das galáxias (2005) fala da necessidade de se ter um guia para transitar pelo universo.

4. O guia dos mochileiros das galáxias (2005), EUA, de Garth Jennings. 
No mundo real, a noção de futuro, tão cara à FC moderna, parece ter desaparecido. O presente é forte e constante. Não há longo prazo. Esse presente realista, que dói também, pode ser evidenciado na FC pós-moderna. O alto nível tecnológico e o baixo nível social são espelhados nos contos e roteiros atuais, transbordando realidades que espantam ou assustam os mais desavisados. Sua similaridade com nossa realidade é tanta, que, em alguns casos, o termo ficção pode até ser revisto.

Décadas atrás, filmes de ficção científica como Zardoz ${ }^{5}$ ou Logan's Run previam o predicamento pós-moderno de hoje: o grupo isolado vivendo uma vida ascética, numa área restrita, anseia pela experiência do mundo real, de barro material.

Até o pós-modernismo, a utopia era uma tentativa de romper com o real do tempo histórico e entrar no Outro atemporal. Com a sobreposição pós-moderna do "fim da história" pela total disponibilidade do passado em memória digital, nesta época em que vivemos a utopia atemporal como a experiência ideológica do dia a dia, a utopia se torna o anseio pela Realidade da própria História, pela memória, pelos traços do passado real, numa tentativa de sair da cúpula fechada e sentir o cheiro da deteriorização da crua realidade?.

Matrix $^{8}$ acentua isso, porque combina utopia com distopia, nossa realidade é apresentada como uma realidade virtual criada por um computador, de maneira que nos restringimos a baterias humanas para a Matriz.

\section{SEGURANÇA NO FUTURO}

Em tempos remotos, estudar e economizar faziam parte de uma garantia de futuro, mesmo que isso estivesse diretamente relacionado com a escravidão do salário. De qualquer forma, hoje essas atitudes já não garantem o futuro, mas apenas um presente momentâneo, repleto de angústias: "Numa sociedade dinâmica, as pessoas passivas murcham"

A FC indica alguns futuros possíveis. Sugere, em seus enredos, que o desespero não é justificável, pois as respostas serão encontradas pelo próprio homo

5. Zardoz (1974), EUA, de Jonh Boorman.

6. Logan's Run [Fuga das Estrelas] (1976), de Michael Anderson.

7. ZIZEK, S. Matrix: ou os dois lados da perversão. In: IRWIN, W. Matrix: bem vindo ao deserto do real. São Paulo: Madras, 2003, p. 280

8. Matrix (1999), de Andy Wachowski e Larry Wachowski.

9. SENNETT, op. cit., p. 103. futurus, talvez "mutantes adolescentes", oriundos de uma mutação de ideias e de conhecimentos, que misturados à criatividade, proporcionariam alternativas ainda inimagináveis para a sociedade em que vivemos. Portanto, o desespero pelo futuro pode não ser justificável, pois as novas gerações poderão encontrar soluções interessantes para os problemas de sua época. Nosso trabalho é criar moldando a história de nossas próprias vidas.

Os adolescentes de hoje se juntam por interesses comuns, seja em um clube, seja em um posto de gasolina, seja através de uma comunidade digital. Têm seus próprios grupos, suas próprias tribos, o que muitas vezes preocupa seus pais, como lembra Sennett, quando comenta sobre um de seus pesquisados: "perseguia-o o receio da falta de disciplina ética, sobretudo o temor de os filhos se tornarem 'pequenos ratos', rondando ao léu pelos estacionamentos 
dos shopping centers à tarde, enquanto os pais permaneciam fora de alcance em seus escritórios" ${ }^{\prime 10}$.

E Maturana acrescenta: "a tragédia dos adolescentes é que começam a viver um mundo que nega os valores que lhes foram ensinados"11. A negação dos adultos acaba sendo um problema. Hoje, os adolescentes se organizam também de outras maneiras. Ficam reunidos por um tipo de som (música) que, para nós, não justifica ou que não explica. Mesmo assim é um mundo de responsabilidades. Se eles estão nesse mundo, é porque eles assim o querem ou há "a emergência de um novo tipo de estudante, com novas necessidades e novas capacidades"12.

Novas soluções poderiam ser aspiradas ou exploradas pelos jovens que um dia serão os donos do mundo. "Como educadores/as, devemos avaliar aquilo que já está ocorrendo em nossas salas de aula, quando os alienígenas entram e tomam seus assentos, esperando (im)pacientemente suas instruções sobre como herdar a terra"13.

\section{EXISTE UM "OUTRO ESTRANHO" NA FICÇÃO CIENTÍFICA?}

A "pílula dourada" de Jacoby, retratando o multiculturalismo da pós-modernidade, nos recorda a "pílula vermelha" de Matrix, como símbolo das muitas possibilidades do que virá a acontecer ou do que decidimos em nossas vidas. O filme demonstra a dualidade entre o escolher a pílula azul ou a vermelha, entre o ficar preso a uma realidade virtual ou acordar para a verdadeira realidade, mesmo que dolorosa. A decisão é difícil, mas o personagem Neo acaba decidindo enfrentar uma realidade ainda mais dura do que a da ficção gestada pela Matrix, a da pílula vermelha. Sem dúvida, uma condição que muitas vezes costumamos enfrentar em nosso cotidiano.

Apesar de Jacoby apresentar o conto de FC 1984, de George Orwell, como sendo uma obra utópica, alguns autores, como Bressand e Distler, apresentam-no como um conto antiutópico ou distópico. No fim do século XX e início do XXI, o discurso vigente das lideranças costumava afirmar que câmaras nas ruas, que geralmente passam despercebidas, são apenas para nossa segurança e não para o controle. Ora, controle e segurança estão intimamente relacionados, como nos alertava Foucault em seu Vigiar e punir. Nesse caso, onde ficaria o livre-arbítrio?

O mesmo vale para os chips epidérmicos de que trata Violação de Privacida$\mathrm{de}^{14}$. O filme, cuja história se desenvolve em um futuro mais ou menos próximo, mostra a vida monótona de um editor de imagens (Robin Willians) que edita lembranças gravadas de pessoas que deixaram de existir. Esse tipo de controle, criticado na trama do filme, vem existindo na prática, onde verificamos chips localizadores nos cartões de crédito ou, nos recentes: chips intraepidérmicos.
10. Ibid., p. 21.

11. MATURANA, H. Emoções e linguagem na educação e na política. Belo Horizonte: Ed. UFMG, 2002, p. 33.

12. GREEN, B.; BIGUM, C. Alienígenas na sala de aula. In: SILVA, T. T. (org.). Alienígenas na sala de aula; uma introdução aos estudos culturais em educação. Petrópolis: Vozes, 1995, p. 209.

13. Id., p. 218.

14. Violação de privacidade (Final CUT) (2004), EUA, de Omar Naim. 
15. Id. Modernidade líquida. Rio de Janeiro: Jorge Zahar Editor, 2001, p. 101.

16. SENNETT, op. cit., p. 54.

17. BAUMAN, Z. O mal estar da pós-modernidade. Rio de Janeiro: Jorge Zahar Editor, 1998, p. 54.

18. Free Jack (1992), EUA, de Geoff Murphy.

19. BAUMAN, Z. Modernidade líquida, cit., p. 104.

20. Vídeo Drome (1983), CANADÁ/EUA, de David Cronemberg. comunicação \& educação • Ano XV||l • número 1 • jan/jun 2013

De certa forma, estes sistemas de rastreamento individual ofendem a "liberdade" dos indivíduos, expondo a ilegitimidade dessas novas formas de controle, mais sutis e imperceptíveis. Os processos foram invertidos do pan-óptico de Foucault para o sinóptico sugerido por Bauman: "A obediência aos padrões tende a ser alcançada hoje em dia pela tentação e pela sedução e não mais pela coerção - e aparece sob o disfarce do livre-arbítrio, em vez de revelar-se como força externa" ${ }^{15}$. O "Grande Irmão" tomou uma nova forma, mais perspicaz do que a prevista por Orwell, maior e invisível, o manipulador das marionetes. "A repulsa à rotina burocrática e a busca da flexibilidade produziram novas estruturas de poder e controle, em vez de criarem as condições que nos libertam"16.

Em se tratando de estranhos e de seu papel na sociedade, Bauman nos alerta para suas possíveis utilidades.

Esses poucos fatos anunciam o novo papel atribuído aos pobres na nova versão da "classe baixa", ou da "classe além das classes": ela não é mais o "exército de reserva da mão de obra" mas, verdadeiramente, a "população redundante". Para que serve? Para o fornecimento de peças sobressalentes para consertar outros corpos? $?^{17}$.

Na FC a "classe baixa" também pode ser vista de forma diferente, todos os que morreram podem ser cobaias do futuro, como verificamos no filme Free Jack ${ }^{18}$, com Mick Jagger e Anthony Hopkins - onde não existe o tráfico de órgãos para peças sobressalentes, mas, em contrapartida, existe o tráfico de corpos inteiros! Espelhando-se nos estranhos de Bauman, um piloto de provas (Emilio Estevez), que historicamente já havia morrido, é raptado um segundo antes de sua morte por viajantes do tempo vindos do futuro. O objetivo deles era utilizá-lo — visto que historicamente estava morto - como hospedeiro de uma nova mente milionária (Hopkins), que recusava aceitar sua morte, mas que podia pagar por toda essa operação.

Numa sociedade sinóptica de viciados em comprar/assistir, os pobres não podem desviar os olhos; não há mais para onde olhar. Quanto maior a liberdade na tela (...) tanto mais irresistível se torna o desejo de experimentar, ainda que por um momento fugaz, o êxtase da escolha ${ }^{19}$.

Vídeo Drome ${ }^{20}$ é a FC que mais se aproxima dessa realidade, mostrando a "classe baixa" totalmente dependente da televisão, a ponto de os estranhos terem que frequentar clínicas públicas especializadas no atendimento dos viciados em raios catódicos.

Nós também esquecemos os estranhos de Bauman, quando mergulhamos em nossa vida diária, quando caminhamos pelas ruas e evitamos certos lugares (ou não lugares), pois sabemos que ali existem os que não queremos lembrar que existem. Lamentavelmente essa imposição pós-moderna está piorando a cada dia, quando, em vez de nos preocuparmos em diminuir a pobreza, em atingir sua raiz, nos preocupamos com a segurança de nós e de nossos filhos. Sempre procuramos o caminho mais fácil, o menos doloroso, o mais egoísta, sem dúvida, e o pior é que não temos vergonha disso. 
Ficção científica: utopia ou distopia? - Carlos Alberto Machado

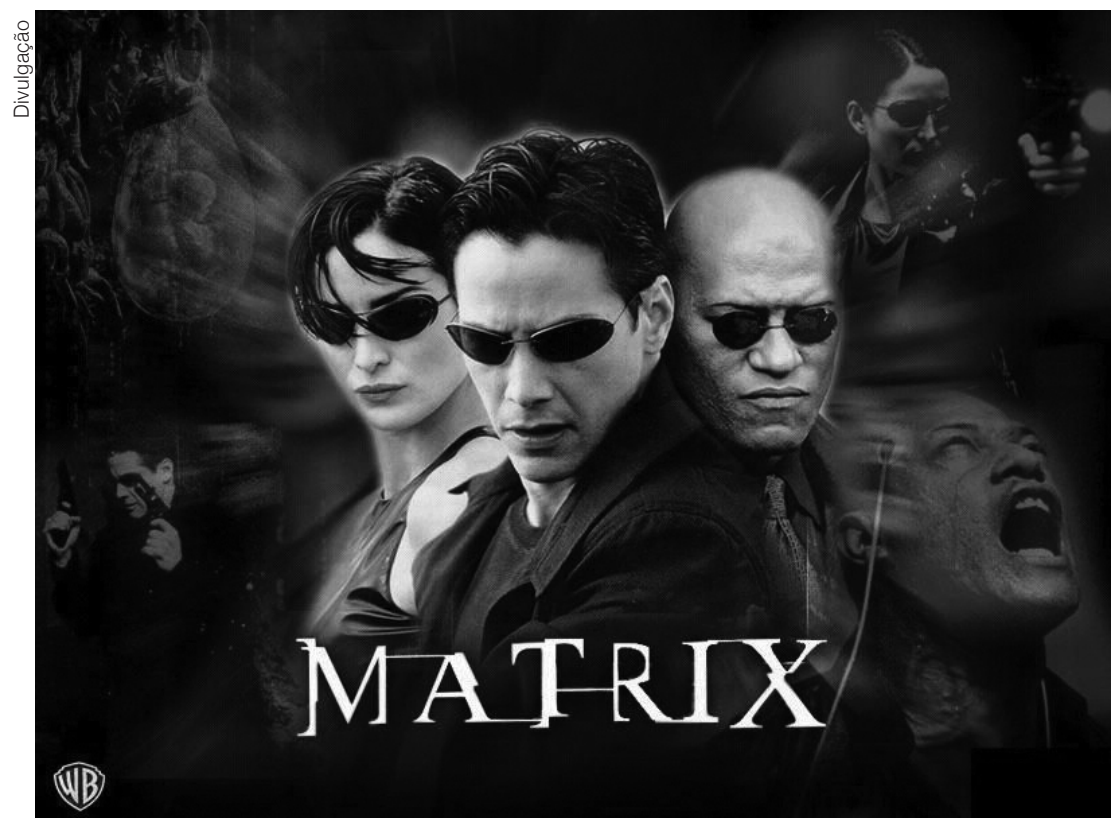

Matrix (1999), combina utopia com distopia.

\section{A IMAGEM DO ESCOLHIDO EM "MATRIX"}

De uma forma análoga à risada enlatada (das comédias de situação na TV), temos aqui algo semelhante a uma dignidade enlatada, em que o Outro (o "Escolhido") retém minha dignidade em meu lugar, ou, mais precisamente, em que eu retenho minha dignidade por meio do Outro. Eu posso ser reduzido à cruel luta pela sobrevivência, mas a própria percepção de que existe o "Escolhido" retém minha dignidade e permite-me manter um elo mínimo com a humanidade ${ }^{21}$.

O escolhido, que pode ser a imagem do pai, do amigo ou do professor, muitas vezes é derrubado ou desmascarado, e nesses casos a vontade de viver desaba, a vontade de sobreviver desaparece com ele, com o outro. Matrix apresenta isso em seu primeiro filme, na imagem de Neo, o protagonista da trilogia. Ele mesmo tinha dúvidas quanto à existência dele ser o outro, o escolhido. Essa dúvida gera tensão entre Neo e seus companheiros, que acabam traindo-o.

\section{SOMOS LIVRES?}

A liberdade "ameaça mais sombria [porém] atormentava o coração dos filósofos: que as pessoas pudessem simplesmente não querer ser livres e rejeitassem a perspectiva da libertação pelas dificuldades que o exercício da liberdade pode acarretar" ${ }^{22}$. Matrix é, sem dúvida, o melhor exemplo das bênçãos mistas da liberdade que podemos encontrar na FC cinematográfica citadas como exemplo na versão apócrifa da Odisseia, em que Ulisses descobre, após 
23. DANAHAY, M. A.; RIEDER, D. Matrix, Marx e a vida de uma bateria. In: IRWIN, op. cit.

24. BAUMAN, Z. Modernidade líquida, cit., p. 126.

25. O Homem Invisível [To See the Invisible Man] (1985), EUA, de Robert Silverberg.

26. Blade Runner, Caçador de Andróides (1982), EUA, de Ridley Scott. comunicação \& educação • Ano XVIII • número 1 • jan/jun 2013

libertar seus "leais" e decepcionados marinheiros, que preferiam continuar na forma de porcos.

Em um momento de clímax do filme, Cypher, um dos protagonistas secundários, para surpresa do público, opta por continuar sendo escravo da máquina, para não perder os prazeres de sua mordomia utópica. Ele está no mundo virtual, sentado à mesa em um restaurante, em frente ao agente Smith, degustando um saboroso filé e negociando sua liberdade e a de seus companheiros ${ }^{23}$. A ilusão foi preferida, em detrimento da realidade nua e crua. Jacoby, parafraseando David Bromwich, pergunta-se: "Os intelectuais se oporiam a escravidão?".

Sair da Caverna de Platão em Matrix é o mesmo que sair do controle das máquinas que dominavam a humanidade. O problema é que, apesar da estonteante realidade demonstrar um conceito de liberdade, existiam pessoas livres que preferiam a liberdade vigiada, retornando à Caverna e preferencialmente, ao contrário de Platão, levando consigo todo o restante, para que ninguém mais pudesse enxergar a verdade. A liberdade aparente que temos ou a liberdade que não queremos.

"Esforços para manter a distância o outro, o diferente, o estranho e o estrangeiro, e a decisão de evitar a necessidade de comunicação" ${ }^{24}$. Na série Além da Imaginação, da década de 1985, o episódio denominado "O Homem Invisível” ${ }^{25}$ retrata exatamente isso. O protagonista Cotter Smith, que feriu a lei de sua cidade cometendo um crime antissocial, leva uma marca em sua testa e, apesar de estar sendo visto pela população, todos fingem não vê-lo e, dessa forma, o personagem sofre as consequências de ser um homem invisível ou um estranho. Apenas quando retirarem sua marca, ou seja, após ter cumprido sua pena, é que voltarão a falar com ele, como se tivesse retornado de uma longa viagem. A sequência final é brilhante: o protagonista avista uma colega com a tal marca, vivendo a mesma situação que ele, e tendo se tornado uma mulher invisível, mas cede às pressões e conversa com ela. Sabia que era apenas questão de tempo para que a marca não tivesse mais efeito cultural.

Jacoby alerta para o fato de que os estadunidenses, apesar do discurso multicultural, não demonstram na prática interesse pelas línguas de outras culturas. Analogamente ao filme, agem como se as outras línguas estivessem portando a marca da invisibilidade social.

Os estranhos de Bauman também podem ser evidenciados no filme distópico Blade Runner [O Caçador de Androides] ${ }^{26}$, em uma história de androides idênticos aos seres humanos que, para escapar do trabalho nas minas do planeta Marte, fogem para a Terra, no intuito de viverem em meio às pessoas, para dessa forma passarem-se por humanos (serem livres). O policial Rick Deckard (Harrison Ford) é contratado pela polícia de Los Angeles (que mais parece uma Hong Kong em decadência) para descobrir onde estão os androides e recapturá-los. Deckard aprofunda-se na investigação e descobre, ao final do filme, que o fato de querer ser humano em uma sociedade decadente como a Terra era impraticável para os androides. Também questiona se os estranhos eram eles, os androides, ou nós, os humanos. A própria identidade de Deckard é 
colocada em dúvida quanto a sua autenticidade humana, por um colega policial Hannibal Chew (James Hong), que a certa altura do filme o trata como um estranho. Essa evidência é demonstrada na cena em que seu colega deixa, em frente ao elevador, uma réplica em papel de um unicórnio, imagem principal implantada nos sonhos de Deckard. Um final para levar muitos a refletirem sobre a situação de Deckard e sobre o rumo que a humanidade pode vir a tomar.

\section{ALGUMA CONCLUSÃO?}

Como toda a encruzilhada evolutiva, não sabemos para onde esta nos levará. As classes dominantes jamais abdicam do poder, mesmo que este as leve à destruição. Assim, inteligências artificiais cada vez mais possantes serão desenvolvidas com o objetivo de serem utilizadas nesse grande xadrez mundial pelo poder, abrindo as portas, talvez, para a nossa destruição $0^{27}$.

A contemporaneidade mostra uma busca pelo prazer diário, mesmo que supérfluo, um consumo no sentido de digerir. Literatura, cinema, jogos virtuais, comida e bebida. Tudo que esteja sendo comentado, divulgado na cultura de massa. Essa fuga pelo consumo não apazigua sua busca por si mesmo, confundido-se com a busca pela sociedade, pelo reconhecimento nela. A busca por si deve ser constante. A dificuldade é que, no meio dessa busca, devemos mudar, e toda mudança implica não só uma perda, mas também aceitar a perda, e não é fácil. O processo de mudança é essencial, mas difícil.

Sennet aponta para a falta de relacionamentos objetivos e duráveis como uma solução para o problema da inquietação e da angústia. Isso também se evidencia nos jogos virtuais de computador, que estão cada vez mais reais e sedutores.

Matrix pode servir de alerta para situações análogas que estão por vir? A escola por sua vez tem que aprender a trabalhar com esse processo de construção social que, além das experiências educacionais, também inclui, como lembra Green e Bigum, os meios de comunicação de massa, rock, cultura da droga e outros fatores subculturais. Eles também recordam que é cada vez mais urgente a necessidade de "pensarmos de forma diferente". Precisamos reimaginar a "imaginação investigativa educacional" 28 .

Dessa forma, os autores concluem que:

argumentamos que é importante interagir ativamente com os novos insights e imagens proporcionados pelo pós-modernismo cultural e pela nova ciência. Como tem sido assinalado por vários analistas [...], parece haver uma convergência geral e extremamente produtiva entre a teoria social e a ficção científica ${ }^{29}$.

Desse modo, explorá-la no conceito educacional, como esse artigo, se torna essencial.

Jacoby, em seu $O$ fim da utopia, admite que a linguagem é reveladora e a diversidade determina os caminhos a serem seguidos. Os conservadores que o negam ficam à beira do caminho.
27. TORRIGO, M. Prólogo a Matrix. In: IRWIN, op. cit., p. 28.

28. GREEN, B.; BIGUM, C. Alienígenas na sala de aula. In: SILVA, T. T. (org.). Alienígenas na sala de aula: uma introdução aos estudos culturais em educação. Petrópolis: Vozes, 1995, p. 211.

29. Id. 
comunicação \& educação • Ano XV|l| • número 1 • jan/jun 2013

\section{REFERÊNCIAS BIBLIOGRÁFICAS}

BAUMAN, Z. O mal-estar da pós-modernidade. Rio de Janeiro: Jorge Zahar Editor, 1998.

. Modernidade líquida. Rio de Janeiro: Jorge Zahar Editor, 2001.

DANAHAY, M. A.; RIEDER, D. Matrix, Marx e a vida de uma bateria. In: IRWIN, Willian. Matrix: bem-vindo ao deserto do real. São Paulo: Madras, 2003.

FOUCAULT, M. Vigiar e punir. 13. ed. Petrópolis: Vozes, 1996.

GREEN, B.; BIGUM, C. Alienígenas na sala de aula. In: SILVA, T. T. (org.). Alienígenas na sala de aula: uma introdução aos estudos culturais em educação. Petrópolis: Vozes, 1995.

IRWIN, W. Matrix: bem-vindo ao deserto do real. São Paulo: Madras. 2003.

JACOBY, R. O fim da utopia: política e cultura na era da apatia. Rio de Janeiro: Record, 2001.

MATURANA, H. Emoções e linguagem na educação e na política. Belo Horizonte: Ed. UFMG, 2002.

MORIN, E. Ciência com consciência. Rio de Janeiro: Bertrand Russel, 1996.

SENNETT, R. A corrosão do caráter: consequências pessoais do trabalho no novo capitalismo. 9. ed. Rio de Janeiro: Record, 2005.

TORRIGO, M. Prólogo a Matrix. In: IRWIN, Willian. Matrix: bem-vindo ao deserto do real. São Paulo: Madras, 2003.

ZIZEK, S. Matrix: ou os dois lados da perversão. In: IRWIN, Willian. Matrix: bemvindo ao deserto do real. São Paulo: Madras, 2003. 